\title{
Could different direct restoration techniques affect interfacial gap and fracture resistance of endodontically treated anterior teeth?
}

\author{
Allegra Comba ${ }^{1} \cdot$ Andrea Baldi $^{2}$ - Carlo Massimo Saratti ${ }^{3}$ - Giovanni Tommaso Rocca ${ }^{3}$ - Carlos Rocha Gomes Torres ${ }^{4}$. \\ Gabriel Kalil Rocha Pereira ${ }^{5}$. Felipe Luiz Valandro ${ }^{5}$ Nicola Scotti ${ }^{6}$
}

Received: 9 September 2020 / Accepted: 19 March 2021 / Published online: 15 April 2021

(C) The Author(s) 2021

\begin{abstract}
Objectives To evaluate different direct restoration techniques on various cavity designs in anterior endodontically treated teeth (ETT).

Materials and methods Ninety upper central incisors $(n=90)$ were selected, endodontically treated, and divided into three groups ( $n=30$ ) accordingly to the cavity design: minimal endodontic cavity access (group A), endodontic access + mesial class III cavity (group B), and endodontic access + two class III cavities (group C). Three subgroups $(n=10)$ were then created accordingly to the restoration technique: nano hybrid composite restoration (subgroup a), glass fiber post + dual-cure luting cement (subgroup b), and bundled glass fiber + dual-cure luting cement (subgroup c). Samples underwent micro-CT scan, chewing simulation, and a second micro-CT scan. 3D quantification $\left(\mathrm{mm}^{3}\right)$ of interfacial gap progression was performed; then, samples underwent fracture resistance test. Data were statistically analyzed setting significance at $p<0.05$.

Results Groups A and B showed significantly lower interfacial gap progression compared with group C. Subgroup b performed significantly better compared with subgroups a and c. Improved fracture strength was reported for group C compared with group A, while both subgroups $\mathrm{b}$ and $\mathrm{c}$ performed better than subgroup $\mathrm{a}$.

Conclusions Cavity design significantly influenced interfacial gap progression and fracture resistance. Fiber posts significantly lowered gap progression and improved fracture resistance while bundled fibers only increased fracture resistance. A significant reduction of non-repairable fractures was recorded when fibers were applied.

Clinical relevance A minimally invasive approach, conserving marginal crests, should be applied whenever possible. Inserting a fiber post is indicated when restoring anterior ETT, in order to reduce gap progression, improve fracture resistance, and avoid catastrophic failures.
\end{abstract}

Keywords 3D interfacial gap $\cdot$ Micro-CT $\cdot$ Fracture resistance $\cdot$ Fracture pattern $\cdot$ Post $\cdot$ Endodontically treated teeth

Nicola Scotti

nicola.scotti@unito.it

1 Department Surgical Sciences, Dental School, University of Turin, Turin, Italy

2 Department of Surgical Sciences, Dental School, University of Turin, Turin, Italy

3 Division of Cariology and Endodontology, School of Dentistry, University of Geneva, Geneva, Switzerland

4 Institute of Science and Technology, Department of Restorative Dentistry, São Paulo State University-UNESP, São José dos Campos, SP, Brazil

5 Department of Restorative Dentistry, Division of Prosthodontics, Federal University of Santa Maria, Santa Maria, Brazil

6 Department of Surgical Sciences, Dental School, University of Turin, Turin, Italy

\section{Introduction}

Restoration of endodontically treated teeth (ETT) remains a challenge for dental clinicians, as the endodontic treatment weakens the tooth structure in terms of biomechanical behavior compared with the vital counterpart. In fact, ETT are more brittle due to structural changes in dentin, loss of water, and weakened collagen cross-linking [1]. These changes lead to increased cuspal deflection during function, with consequent higher occurrence of fractures $[2,3]$. For this reason, postendodontic restoration challenge is to recover the biomechanical behavior of the tooth and prevent catastrophic fractures.

Several types of restorations have been proposed in literature to restore and reinforce ETT. In the past, traditional full coverage crowns in combination to metal post 
showed enhanced longevity, in the expense of an invasive procedure [4-6]. Thanks to the introduction of adhesive techniques, less invasive procedures are nowadays available to restore compromised teeth. Recent studies reported that the mechanical resistance and the longevity of ETT directly depend on the amount of residual tooth structure, meaning that a minimally invasive approach should be applied whenever possible. Direct resin composite restorations represent the least invasive approach in order to preserve the much sound structure possible. For this reason, they have been frequently studied to evaluate their efficacy when restoring an ETT, showing a significant increase in fracture resistance when the direct restoration was reinforced by fiber posts [7-10]. This trend was also confirmed by the in vivo evidence that highlighted a positive correlation between post-insertion and restoration longevity [11-13]. However, despite a great evidence regarding posterior teeth, few information concerning the direct restoration efficacy in endodontically treated anterior teeth is available.

In addition to the previously introduced concepts, it has to be considered that anterior restorations are subjected to high masticatory loads and parafunctional forces. Thus, fracture is a relatively common clinical failure that occur over time [14, 15]. A recent review by Heintze et al. reported that the lack of mechanical retention in class IV restoration must be considered an adhesive challenge and seems to lead to twice as high failure rate than class III restorations. A higher prevalence of failure in class IV restorations in bruxers was also reported by van Dijken et al. [16], showing that overloading and increased mechanical stresses in the restorations are making them more prone to fracture and secondary caries.

The evaluation of a direct restoration efficacy should not be focused on the tooth structure reinforcement effect only. Indeed, occlusal stresses generated during mastication and, especially, during parafunctional activities, such as bruxism, were shown to have a deleterious effect on the marginal adaptation of composites [17]. These mechanical stresses repeated over time lead to fatigue weakening of the adhesive interface, ultimately generating a gap that may further lead to microleakage [18]. Even if a direct correlation between microleakage and clinical parameters has not been proved [19], gaps that exceed a width of $60 \mu \mathrm{m}$ could possibly lead to bacteria accumulation, ultimately leading to sensitivity and increased chance of secondary caries [20-22].

The aim of the present in vitro study was to evaluate the effect of different direct restoration techniques on endodontically treated anterior teeth with different cavity designs, analyzing interfacial gap and fracture resistance. The null hypothesis tested was that the cavity design (1) and the restoration technique (2) do not affect the interfacial gap and the fracture resistance of endodontically treated central incisors.

\section{Materials and methods}

\section{Sample preparation}

Ninety upper central incisors $(n=90)$ with similar crown and root size (length $>14 \pm 2 \mathrm{~mm}$ ), extracted within 4 months for periodontal reasons, were selected. Manual scaling was performed for surface debridement, followed by cleaning with a rubber cup and pumice. Specimens were disinfected in $0.5 \%$ chloramine for $48 \mathrm{~h}$ and then stored in $4 \%$ thymol solution at room temperature until use. Samples were double-checked with optical $4.5 \times$ magnification to exclude teeth with caries, previous restorations and visible cracks.

Selected teeth were endodontically treated using Pathfiles and ProTaper Next (Dentsply Maillefer, Ballaigues, Switzerland) to the working length, set at $1 \mathrm{~mm}$ short of the visible apical foramen. Irrigation was performed with $5 \%$ $\mathrm{NaOCl}$ (Niclor 5, Ogna, Muggiò, Italy) alternated with $10 \%$ EDTA (Tubuliclean, Ogna, Muggiò, Italy). The root canals were filled with gutta-percha cones trough a warm vertical condensation technique.

Specimens were then divided into three groups $(n=30$ each) accordingly to the cavity design, which were performed by the same experienced operator.

- Group A: specimens exclusively presented a minimal endodontic cavity access at the cingulum level. Guttapercha was removed up to $3 \mathrm{~mm}$ below the cementoenamel junction (CEJ).

- Group B: additionally to the cavity access, a single class III cavity was prepared on the mesial side using an eggshaped diamond bur. To ensure reproducible cavity dimensions as much as possible, the mesio-distal, linguobuccal, and cervical-incisal extents of the tooth crown were measured with a caliper. Class III cavities included one third of the mesio-distal and linguo-buccal lengths and one quarter of the cervical-incisal extent. The cervical margin of the cavity was performed in enamel, ensuring a distance to the CEJ of $1 \mathrm{~mm}$. Due to the selected mesiodistal dimension, the median part of the cavity was always connected to the endodontic cavity access.

- Group C: same as group B, but two class III cavities were prepared on mesial and distal side of each sample.

After cavity preparation, specimens were divided into three subgroups accordingly to the employed restoration technique $(n=10$ each):

- Subgroup a: Cavity was etched with phosphoric acid (Conditioner 36, Dentsply, Konstanz, Germany) for 15 $\mathrm{s}$, rinsed with water, and air-dried. A universal adhesive (Futurabond U, Voco, Cuxhaven, Germany) was applied uniformly at all cavity surfaces for $20 \mathrm{~s}$ using a micro 
brush, air-dried for $5 \mathrm{~s}$, and light-cured for $20 \mathrm{~s}$ with a multiLED lamp (1400 $\mathrm{mW} / \mathrm{cm}^{2}$; Bluephase Style, Ivoclar, Schaan, Luxembourg). A direct restoration with nano hybrid composite (Filtek Supreme XTE, 3M) was performed applying 2-mm-thick layers with horizontal layering technique.

- Subgroup b: Post-space was prepared with dedicated drills for a total of $8 \mathrm{~mm}$ depth (Rebilda Post Drill, diameter $1.2 \mathrm{~mm}$ ). A dedicated fiber post (Rebilda Post, Voco) was luted with a dual-cure luting cement (Rebilda GT, Voco) following manufacturer instruction. After lightcuring for $40 \mathrm{~s}$ with a multiLED lamp $\left(1400 \mathrm{~mW} / \mathrm{cm}^{2}\right.$; Bluephase Style, Ivoclar), a direct composite restoration was performed as described for subgroup a.

- Subgroup c: Same as subgroup b, but using a bundled glass-fiber-reinforced composite post (Rebilda Post GT, Voco).

All the restored specimens were finished and polished with fine-grit diamond burs and silicon points in order to obtain a smooth surface without over or under contouring, and then stored in distilled water. Figure 1 schematically reports the study design.

\section{Micro-CT analysis and cyclic fatigue test}

Each sample underwent a micro-computed tomography (micro-CT) scan (SkyScan 1172; Bruker, Billerica, MA, USA) to evaluate interfacial gap. High-resolution scans were performed using the following parameters: voltage $=100 \mathrm{kV}$, current $=100 \mu \mathrm{A}$, aluminum and copper $(\mathrm{Al}+\mathrm{Cu})$ filter, pixel size $=15 \mu \mathrm{m}$, averaging $=5$, rotation step $=0.5^{\circ}$. Images were reconstructed though NRecon software (Bruker, Billerica,
MA, USA) in order to obtain DICOM files, with standardized parameters: beam hardening correction $=20 \%$, smoothing $=$ 3 , ring artifact reduction $=9$.

A CS-4.4 chewing simulator (SD Mechatronik; Feldkirchen- Westerham, Germany) was used for mechanical aging of the specimens. A 4-mm diameter metal cone was employed, using the following parameters: occlusal load = $50 \mathrm{~N}$, frequency $=1 \mathrm{~Hz}$, downward speed $=16 \mathrm{~mm} / \mathrm{s}$, and $2 \mathrm{~mm}$ sliding movement. The movement pattern was set from the palatal cingulum towards the incisal edge. The test was performed for 500,000 cycles in water at room temperature.

To reveal interfacial gap progression between the restoration and the tooth structure after cyclic fatigue, samples were subjected to a second scan with same baseline parameters to ensure consistency in the grayscale values. Initial scans were then reconstructed with NRecon using the same protocol and aligned with post-chewing scans using DataViewer TM software (Bruker, Billerica, MA, USA). Thresholding was performed automatically with Mimics Medical 20.0 software (Materialise, Ann Arbor, MI, USA), in order to obtain a void mask representing gaps and voids inside the tooth-restoration complex, with external boundaries set at $1 \mathrm{~mm}$ from the direct restoration. A Hounsfield unit (HU) range of 1024 to 950 was selected to maximize void visualization. The volume of the mask was automatically calculated by the software and recorded in $\mathrm{mm}^{3}$. In order to specifically analyze gap progression and exclude composite internal bubble volume, the result obtained from the baseline scan was subtracted from the volume of the second scan. Figure 2 reports the $3 \mathrm{D}$ rendering of a random sample (restoration and voids), seen from the inner surface (in contact with the tooth), before and after chewing simulation.
Fig. 1 Schematic representation of the present study sample preparation protocol

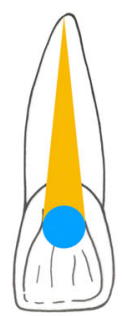

Aa

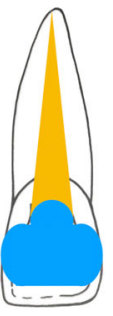

Ca

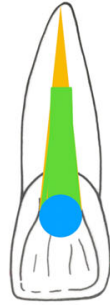

Ab

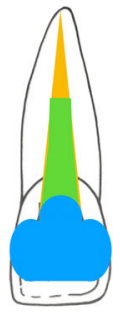

Cb

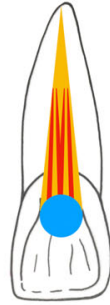

Ac

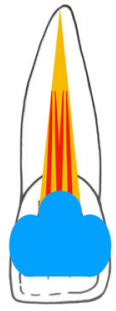

cc

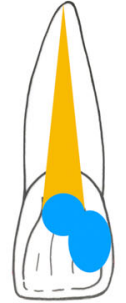

$\mathrm{Ba}$

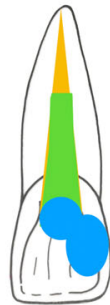

$\mathrm{Bb}$

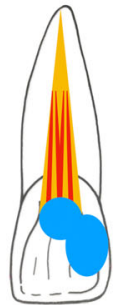

Bc
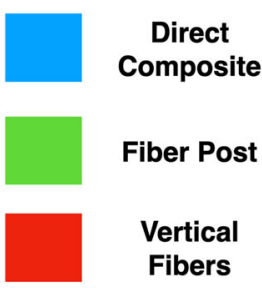

Group A: Endo Access

Group B: Endo Access +1 Proximal

Group C: Endo Access +2 Proximal 


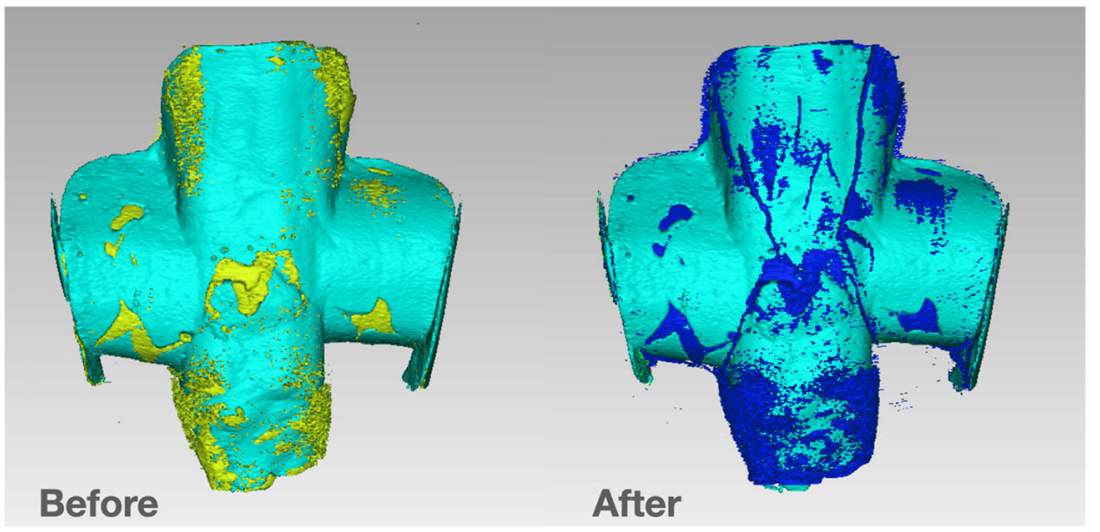

Fig. 2 Random sample before (left) and after (right) chewing simulation. Light blue volume represents the restoration, seen from the inner surface. Yellow volume represents baseline void volume, while blue volume represents final void volume after cyclic fatigue. It is noticeable that many

\section{Fracture resistance test and failure mode analysis}

Samples were then submitted to a static fracture resistance test using a universal testing machine (Instron 10-S; Canton, MA, USA) with a 4-mm diameter metal cone crosshead welded to a tapered shaft and applied to the sample at a constant speed of $0.5 \mathrm{~mm} / \mathrm{min}$ and an angle of $30^{\circ}$ to the long axis of the tooth. Load was applied on the palatal cingulum until fracture and the maximum breaking loads were recorded in Newton $(\mathrm{N})$.

Broken specimens were analyzed under a stereomicroscope (SZX9; Olympus Optical Co., Ltd., Tokyo, Japan). The types of failure were determined and compared, distinguishing between catastrophic fractures (non-reparable, below the CEJ) and non-catastrophic fractures (reparable, above the CEJ). Figure 3 reports two different fractures, as well as a schematic representation for clarification.

\section{Statistical analysis}

To examine the effects of the factors "cavity design" and "restoration technique" on interfacial gap progression and the fracture resistance, a two-way analysis of variance test areas underwent degradation due to mechanical stresses and crack lines appeared. To specifically analyze interfacial gap progression, final data recorded consisted in blue volume minus yellow volume

(ANOVA) was conducted. Post hoc pairwise comparison was performed using Tukey test. All statistical analyses were performed using STATA software (ver. 12.0; StataCorp, College Station, TX, USA).

\section{Results}

Interfacial gap progression data, expressed as means \pm standard deviation in $\mathrm{mm}^{3}$, and fracture resistance, expressed in $\mathrm{N}$, are summarized, respectively, in Table 1 and Table 2. Twoway ANOVA showed that interfacial gap was significantly related to the cavity design $(p<0.001)$ as well as to the restoration technique $(p<0.001)$, as well as the interaction between the two factors $(p<0.001)$. Tukey post hoc test revealed that groups A and B showed significantly lower interfacial gap increase after cyclic fatigue compared with group C and subgroup $b$ showed significantly reduced gap formation compared with subgroups a and c.

Concerning fracture resistance, two-way ANOVA showed a significance difference both for the factor "cavity design" ( $p$
Fig. 3 Random fractures recorded among samples. Notice how CEJ was taken as a reference point to distinguish reparable and non-reparable fractures
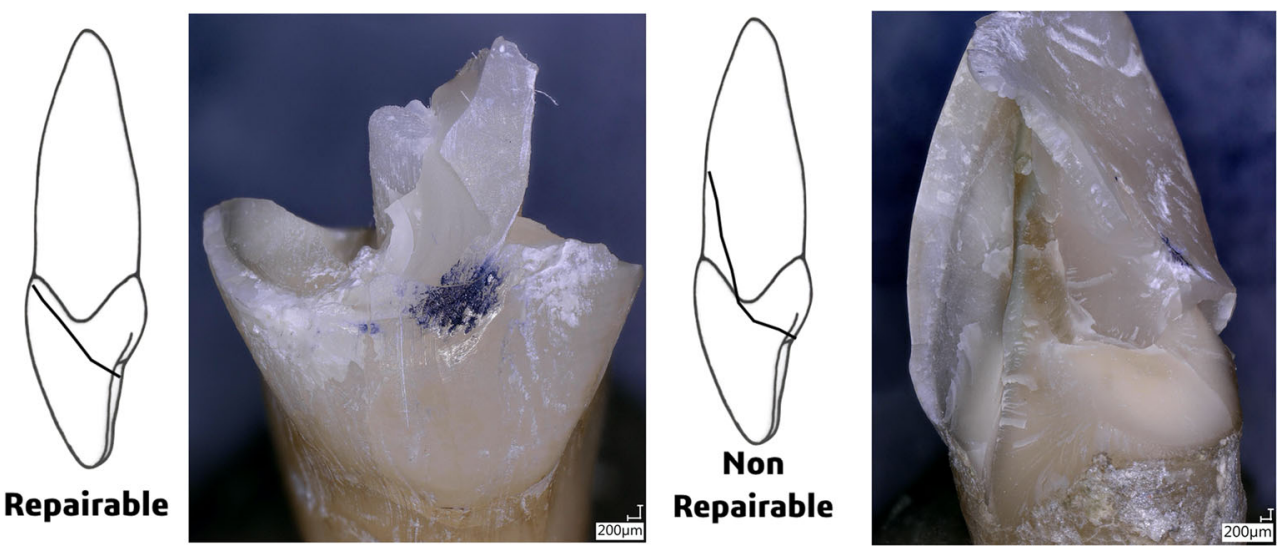
Table 1 Mean interfacial gap variations \pm standard deviation, expressed as $\mathrm{mm}^{3}$, for each group and subgroup

\begin{tabular}{llll}
\hline & $\begin{array}{l}\text { Subgroup a } \\
\text { (no post) }\end{array}$ & $\begin{array}{l}\text { Subgroup b } \\
\text { (fiber post) }\end{array}$ & $\begin{array}{l}\text { Subgroup c } \\
\text { (bundled fibers) }\end{array}$ \\
\hline Group A (endodontical access) & $0.12 \pm 0.06$ & $0.29 \pm 0.09$ & $0.27 \pm 0.08$ \\
Group B (mesial class III cavity) & $0.27 \pm 0.09$ & $0.19 \pm 0.08$ & $0.22 \pm 0.07$ \\
Group C (mesial and distal class III cavities) & $0.67 \pm 0.19$ & $0.35 \pm 0.10$ & $0.48 \pm 0.15$ \\
\hline
\end{tabular}

$=0.023)$ and for the factor "restoration technique" $(p<0.001)$. The Tukey post hoc test highlighted statistical improved fracture strength for subgroup $\mathrm{b}(p<0.001)$ and $\mathrm{c}(p=0.005)$ compared with the subgroup a. Concerning the cavity design factor, Tukey test showed statistical significance when group $\mathrm{C}$ was compared with group A $(p=0.005)$, with group $\mathrm{C}$ performing significantly worse (lower fracture resistance). Recorded fracture patterns, classified between repairable and non-repairable, are reported in Table 3.

After an accurate analysis of the reconstructed images, it was also observed, from a qualitative point of view, that some of the samples randomly presented pre-existent micro-cracks, not visible at $4.5 \times$ magnification, which propagated as a consequence of chewing simulation. Micro-cracks showed a tendency to continue inside the composite buildup when no fibers were applied (subgroup a) compared with samples reinforced with fibers (subgroups b and c). Figure 4 illustrates an example of this trend, showing the propagation of initial microcracks in two random samples from subgroups a and c, before and after chewing simulation.

\section{Discussion}

Clinical studies already demonstrated that incisors and canines have an overall higher failure rate compared with posterior teeth, as the occlusal forces are more transverse [23, 24]. The cyclic fatigue derived from chewing, especially transversal forces, causes a progressive degradation and therefore "opening" of the adhesive interface $[17,18]$. The consequent marginal leakage is of critical concern when referring to composite restorations since it might lead to secondary caries and cracks, letting the tooth more prone to fracture [20, 21]. Moreover, in ETT, marginal leakage led to a potential bacterial recolonization of the root canal system, ultimately causing endodontic failure [25].
Basaran et al. showed that a percentage of dye leakage at the interface between the post and the root canal was always present, regardless of the fiber post or the adhesive technique employed [26]. However, to date, two-dimensional techniques for the analysis of the interfaces are to be considered obsolete and limited compared with three-dimensional investigation methods. A recent technique to detect interfacial gaps is represented by $\mu \mathrm{CT}$, which allows, without destroying the specimen, to generate $3 \mathrm{D}$ images. The number of studies using $\mu \mathrm{CT}$ in restorative dentistry is increasing, as this technique has proved effective for the evaluation of internal adaptation of composite resin restoration [27-32]. In the present study, cyclic intermittent loading induced an interfacial gap opening in all specimens, corroborating in vivo and in vitro previous findings that showed functional and parafunctional stresses, especially transversal forces, are able to cause marginal gap opening on adhesive interfaces [17, 18].

Based on the present study results, the cavity extension as well as the use of fiber post were crucial in reducing the interfacial gap progression after cyclic fatigue; thus, the first null hypothesis was rejected. Interfacial gap openings occur during fatigue when cyclic forces induce a tooth flexion which is higher in non-vital teeth due to their reduced stiffness [33]. Loss of tooth structure is a key factor for stress resistance of endodontically treated teeth, in anterior as well as in posterior teeth. As demonstrated by Reeh et al. referring to premolars, the loss of marginal ridges can lead to a diminished fracture resistance going from 44 to $66 \%$ [33]. Obviously, if more tooth structure is preserved, cyclic forces find a higher resistance to flexion, thus leading to less interfacial gap formation. The present study showed that the loss of one or two marginal ridges is immediately correlated to increased interfacial gap, because they represent the anatomical portion in anterior teeth that provides resistance to traversal loads. The use of a fiber post is indeed crucial when extended cavities are present as their mechanical properties are close to the dentin [34, 35]. Consequently, they can reproduce the natural load
Table 2 Mean fracture resistance \pm standard deviation, expressed in Newton (N), for each group and subgroup

\begin{tabular}{llll}
\hline & $\begin{array}{l}\text { Subgroup a } \\
\text { (no post) }\end{array}$ & $\begin{array}{l}\text { Subgroup b } \\
\text { (fiber post) }\end{array}$ & $\begin{array}{l}\text { Subgroup c } \\
\text { (bundled fibers) }\end{array}$ \\
\hline Group A (endodontical access) & $542.6 \pm 207.2$ & $667.2 \pm 243.3$ & $660.4 \pm 231.7$ \\
Group B (mesial class III cavity) & $507.7 \pm 143.1$ & $718.7 \pm 149.7$ & $643.6 \pm 208.8$ \\
Group C (mesial and distal class III cavities) & $335.8 \pm 86.5$ & $663.1 \pm 166.3$ & $537.8 \pm 108.2$ \\
\hline
\end{tabular}


Table 3 Fracture patterns for each group and subgroup, divided between repairable (rep) and nonrepairable (non-rep)

\begin{tabular}{|c|c|c|c|c|c|c|}
\hline & \multicolumn{2}{|c|}{$\begin{array}{l}\text { Subgroup a (no } \\
\text { post) }\end{array}$} & \multicolumn{2}{|c|}{$\begin{array}{l}\text { Subgroup b (fiber } \\
\text { post) }\end{array}$} & \multicolumn{2}{|c|}{$\begin{array}{l}\text { Subgroup c } \\
\text { (bundled fibers) }\end{array}$} \\
\hline & Rep & Non-rep & Rep & Non-rep & Rep & Non-rep \\
\hline Group A (endodontical access) & 2 & 8 & 8 & 2 & 7 & 3 \\
\hline Group B (mesial class III cavity) & 2 & 8 & 8 & 2 & 8 & 2 \\
\hline Group C (mesial and distal class III cavities) & 0 & 10 & 7 & 3 & 5 & 5 \\
\hline
\end{tabular}

transmission mechanisms to the tooth structure reducing the risk and entity of gap formation. Moreover, an increased flexural strength when using a fiber post compared with composite-only build-up has already been demonstrated by several authors [36]. The higher flexural strength of fiber post might mediate loads between dentin and restoration materials, therefore resulting in a more homogenous stress distribution [37]. On the other hand, the placement of vertical bundled glass fibers within the root canal did not significantly reduce the gap increase during cyclic fatigue, probably due to the lower flexural strength of this restorative solution if compared with the traditional glass fiber post.

Possible ways to restore compromised ETT were studied and analyzed in the past by many authors [4, 38, 39], who demonstrated an important reduction in tooth fracture when a full coverage crown was performed. However, this option is very demanding in terms of economical and biological costs for the patient. This concept is particularly true when referring to anterior teeth, whose fracture resistance is similarly correlated to the presence of residual tooth structure [40, 41], but it is subjected to different biomechanical stresses during function and parafunction.

The present study results clearly showed that the cavity configuration in anterior teeth is directly correlated to the fracture resistance, which could be partially recovered by using a fibersupported composite restoration. Thus, the second null hypothesis was rejected. It has been recently suggested, in order to improve fracture resistance in ETT, to insert fibers within direct resin composite restorations $[42,43]$. Thanks to their elastic modulus similar to dentin and stress bearing capabilities, fibers might reinforce the structure and lead to fewer root fractures. Literature, however, is not unanimous about the usage of fibers, with studies affirming that there is no significant difference in the use of a classic composite build-up and its corresponding post system [44]. On the other hand, other authors affirm that for anterior ETT, fiber post-placement seems advisable to improve static load resistance, especially in cases with extensive loss of coronal tissues [45]. This is in accordance with the present study results, which reported ETT performing significantly better in fracture resistance test when a post or vertical bundled fibers were used. This reinforcement effect was mainly advisable in group $\mathrm{C}$, probably because buccal enamel, incisal margin, and oral cingulum are less involved in the tooth structure reinforcement compared with proximal ridges. This could also explain the different results obtained by Lausnitz et al.: a less invasive cavity design surely helps the specimen in resisting both fatigue cycles and fracture loads [46]. This is also accordance with the results of Vadini et al. that reported a significant benefit in resistance to static loads
Fig. 4 The first row shows a random sample $(\mathrm{Ca})$ before and after chewing simulation. It is noticeable that cracks propagated from the tooth structure to the buildup itself. The second row shows another sample reinforced with fibers $(\mathrm{Cc})$, where the crack propagation is clearly limited to the tooth structure
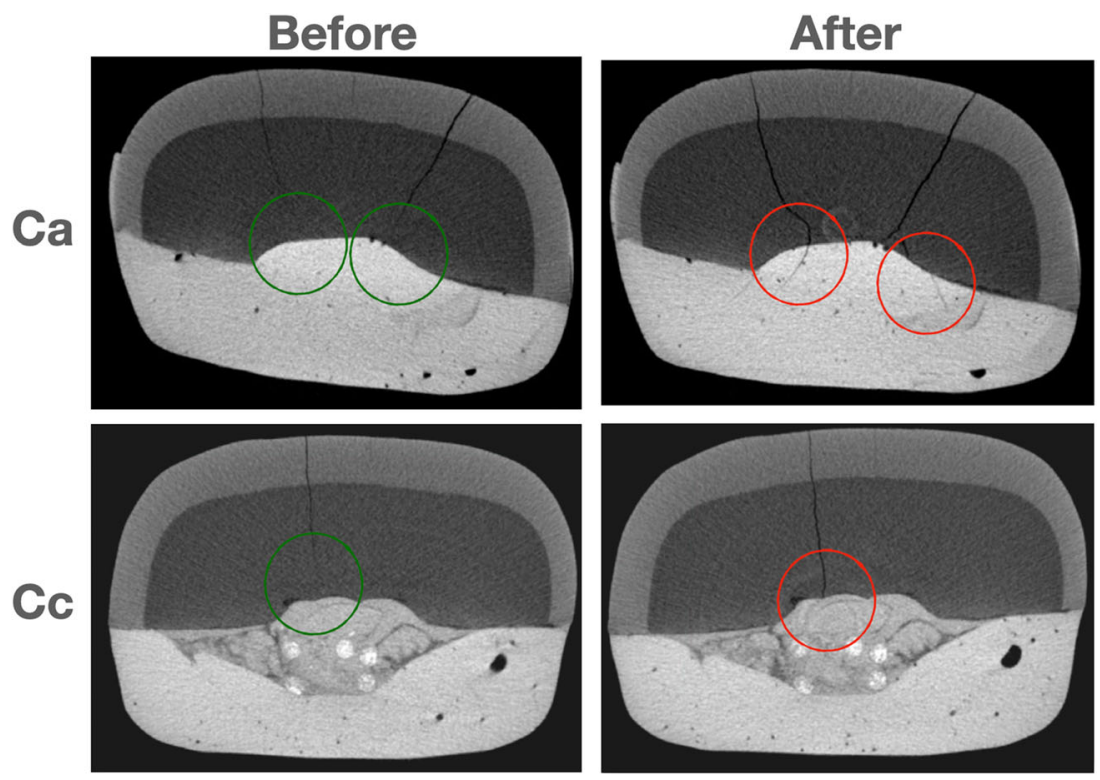
when a post was placed, particularly in cavity designs with extensive loss of coronal tissues (two class II cavities) [45]. Anyway, further studies should focus and evaluate the contribution to the resistance to occlusal loads of the anatomical components of the anterior teeth in order to better understand the impact of cavity configuration and extension on their resistance to fatigue phenomena.

As demonstrated by Newman et al. [47], fiber-supported composite appears to dissipate forces along the root canal system, reducing peak stresses on the root and therefore moving the critical fracture point coronally, ultimately leading to repairable fractures $[48,49]$. On the other hand, rigid posts such as carbon fiber or cast posts and core seem to be more prone to cause nonrepairable root fractures due to their elastic modulus [50]. Hayashi et al. studied the fracture mode when teeth restored with different post system were subjected to oblique and vertical load, concluding that vertical loadings caused crack propagation in the middle and apical portion of the roots, while with oblique loads, most of the fractures occurred in the cervical part of the root when fiber posts were used, and in the middle part, when prefabricated metallic or cast metallic post-core were used [51]. Chieruzzi et al. showed that when a fiber-post is used, the stress generated through dentin, cement, and post is well-distributed and without any relevant peak. Therefore, it can be concluded that the use of glass fiber allows to simulate the mechanical behavior of natural tooth [52]. The fracture pattern analysis performed in the present study confirmed previous findings, as all samples restored with fiber posts showed more favorable fracture patterns. In this context, vertical bundled fibers showed better performance compared with a direct composite restoration, but inferior performances compared with fiber post-supported composite restoration, especially where an extensive loss of structure was simulated.

Lastly, in some sample, it has been noted that fiber seems to limit or avoid the propagation of micro-cracks, as previously shown in Fig. 4, ultimately acting as force-breakers. In most of the samples of subgroup a (no post), the propagation of dentinal cracks, which were randomly present before cyclic fatigue test, continued in the composite restoration, while in subgroups $b$ and c, fibers were able to block or reduce this trend. This data could be important to understand the resistance to cyclic loads, even considering that the majority of dental restorations fail under subcritical, cyclic occlusal loads over an extended period of time, during which the interfacial bond degrades progressively.

\section{Conclusions}

Based on the obtained results, it can be concluded that:

- Cavity design significantly influences interfacial gap progression, fracture resistance, and fracture pattern.
- Fiber post-supported composite significantly reduced gap progression and improved fracture resistance of ETT anterior teeth. Thus, the insertion of a fiber post is indicated, even to improve the probability of a favorable fracture pattern.

- Vertical bundled fibers were not able to reduce interfacial gap progression significantly, but they increased fracture resistance and slightly improved fracture pattern, even if not as much as conventional fiber post.

Further in vitro studies are necessary to evaluate the crack propagation during fatigue.

Acknowledgements Authors gratefully thank Dr. Edoardo Alberto Vergano for his precious contribution in this research.

Author contribution Scotti Nicola: Coordinator of the research project and manuscript supervisor.

Comba Allegra, Baldi Andrea, Saratti Carlo Massimo: Sample preparation and laboratory test.

Comba Allegra: Statistical analysis.

Torres Carlos Rocha Gomes, Pereira Gabriel Kalil Rocha, Valandro Luiz Felipe: Manuscript revision.

Comba Allegra and Rocca Giovanni Tommaso: Manuscript writer.

Funding Open access funding provided by Università degli Studi di Torino within the CRUI-CARE Agreement. This research did not receive any specific grant from funding agencies in the public, commercial, or not-for-profit sectors.

\section{Declarations}

Ethical approval This article does not contain any studies with human participants or animals performed by any of the authors.

Informed consent For this type of study, formal consent is not required. All authors confirm that the paper has been submitted solely to "Clinical Oral Investigation" and that it is not under consideration for publication in any other journals.

Conflict of interest The authors declare no competing interests.
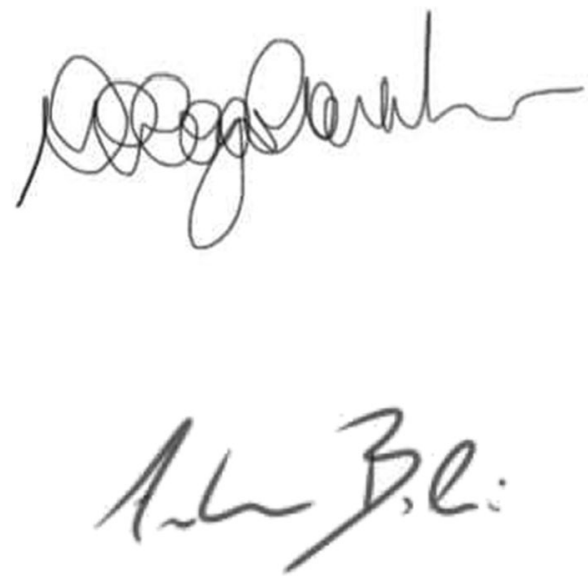

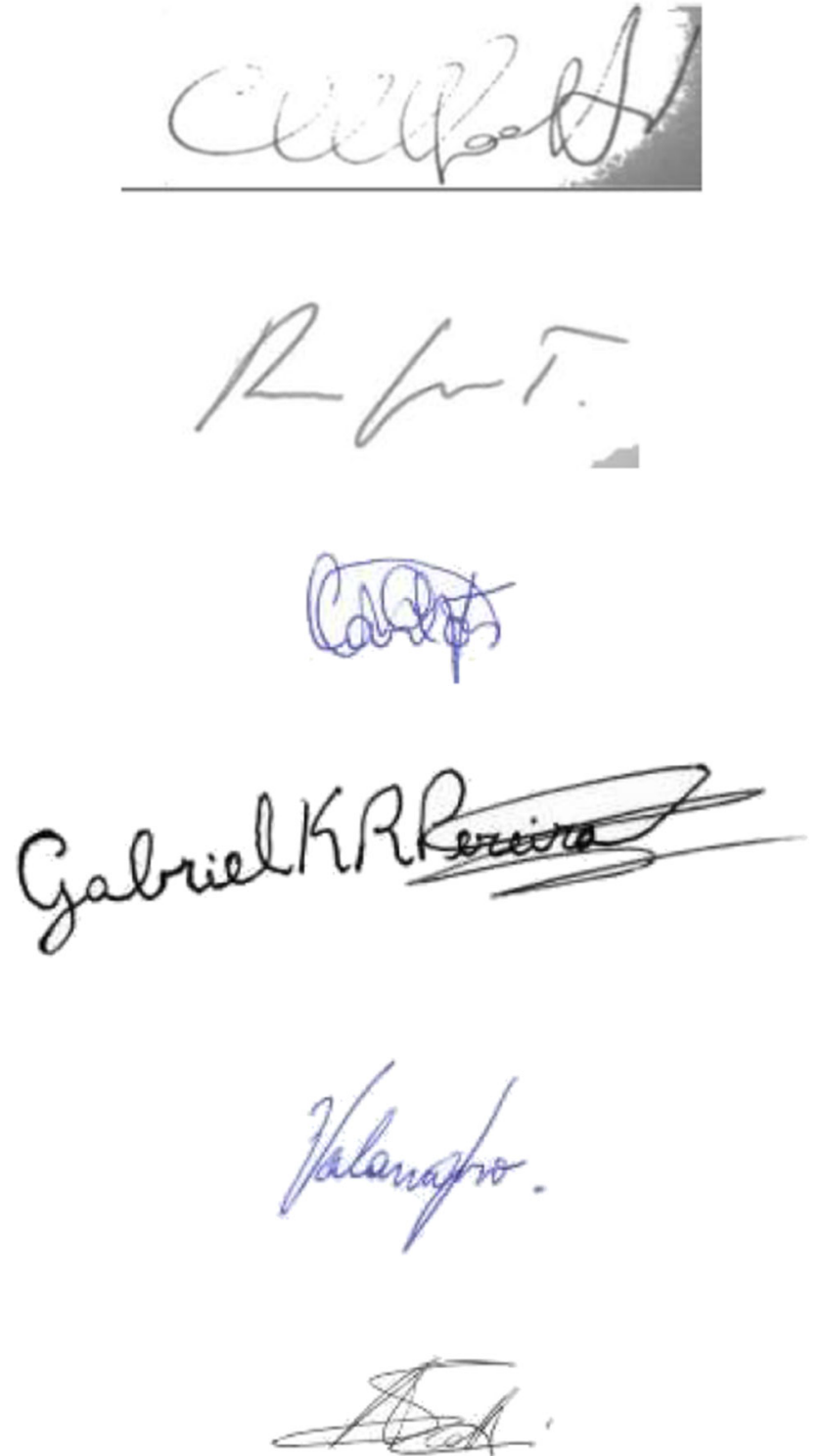

Open Access This article is licensed under a Creative Commons Attribution 4.0 International License, which permits use, sharing, adaptation, distribution and reproduction in any medium or format, as long as you give appropriate credit to the original author(s) and the source, provide a link to the Creative Commons licence, and indicate if changes were made. The images or other third party material in this article are included in the article's Creative Commons licence, unless indicated otherwise in a credit line to the material. If material is not included in the article's Creative Commons licence and your intended use is not permitted by statutory regulation or exceeds the permitted use, you will need to obtain permission directly from the copyright holder. To view a copy of this licence, visit http://creativecommons.org/licenses/by/4.0/.

\section{References}

1. Pontius O, Nathanson D, Giordano R, Schilder H, Hutter JW (2002) Survival rate and fracture strength of incisors restored with different post and core systems and endodontically treated incisors without coronoradicular reinforcement. J Endod 28:710-715. https://doi.org/10.1097/00004770-200210000-00008
2. Assif D, Gorfil C (1994) Biomechanical considerations in restoring endodontically treated teeth. J Prosthet Dent 71:565-567. https:// doi.org/10.1016/0022-3913(94)90438-3

3. Larson TD, Douglas WH, Geistfeld RE (1981) Effect of prepared cavities on the strength of teeth. Oper Dent 6:2-5

4. Aquilino SA, Caplan DJ (2002) Relationship between crown placement and the survival of endodontically treated teeth. J Prosthet Dent 87:256-263

5. Tang W, Wu Y, Smales RJ (2010) Identifying and reducing risks for potential fractures in endodontically treated teeth. J Endod 36: 609-617. https://doi.org/10.1016/j.joen.2009.12.002

6. Sorensen JA, Martinoff JT (1985) Endodontically treated teeth as abutments. J Prosthet Dent 53:631-636. https://doi.org/10.1016/ 0022-3913(85)90008-3

7. Scotti N, Rota R, Scansetti M, Paolino DS, Chiandussi G, Pasqualini D, Berutti E (2013) Influence of adhesive techniques on fracture resistance of endodontically treated premolars with various residual wall thicknesses. J Prosthet Dent 110:376-382. https://doi.org/10.1016/j.prosdent.2013.08.001

8. Mohammadi N, Kahnamoii MA, Yeganeh PK, Navimipour EJ (2009) Effect of fiber post and cusp coverage on fracture resistance of endodontically treated maxillary premolars directly restored with composite resin. J Endod 35:1428-1432. https://doi.org/10.1016/j. joen.2009.07.010

9. Sorrentino R, Salameh Z, Zarone F, Tay FR, Ferrari M (2007) Effect of post-retained composite restoration of MOD preparations on the fracture resistance of endodontically treated teeth. J Adhes Dent 9:49-56

10. Scotti N, Scansetti M, Rota R, Pera F, Pasqualini D, Berutti E (2011) The effect of the post length and cusp coverage on the cycling and static load of endodontically treated maxillary premolars. Clin Oral Investig 15:923-929. https://doi.org/10.1007/ s00784-010-0466-y

11. Bitter K, Noetzel J, Stamm O, Vaudt J, Meyer-Lueckel H, Neumann K, Kielbassa AM (2009) Randomized clinical trial comparing the effects of post placement on failure rate of postendodontic restorations: preliminary results of a mean period of 32 months. J Endod 35:14771482. https://doi.org/10.1016/j.joen.2009.07.026

12. Scotti N, Eruli C, Comba A, Paolino DS, Alovisi M, Pasqualini D, Berutti E (2015) Longevity of class 2 direct restorations in rootfilled teeth: a retrospective clinical study. J Dent 43:499-505. https://doi.org/10.1016/j.jdent.2015.02.006

13. Naumann M, Koelpin M, Beuer F, Meyer-Lueckel H (2012) 10year survival evaluation for glass-fiber-supported postendodontic restoration: a prospective observational clinical study. J Endod 38: 432-435. https://doi.org/10.1016/j.joen.2012.01.003

14. de Moura FRR, Romano AR, Lund RG et al (2011) Three-year clinical performance of composite restorations placed by undergraduate dental students. Braz Dent J 22:111-116. https://doi.org/ 10.1590/s0103-64402011000200004

15. Baldissera RA, Corrêa MB, Schuch HS, Collares K, Nascimento GG, Jardim PS, Moraes RR, Opdam NJM, Demarco FF (2013) Are there universal restorative composites for anterior and posterior teeth? J Dent 41:1027-1035. https://doi.org/10.1016/j.jdent.2013. 08.016

16. van Dijken JWV, Pallesen U (2010) Fracture frequency and longevity of fractured resin composite, polyacid-modified resin composite, and resin-modified glass ionomer cement class IV restorations: an up to 14 years of follow-up. Clin Oral Investig 14:217222. https://doi.org/10.1007/s00784-009-0287-z

17. Qvist V (1983) The effect of mastication on marginal adaptation of composite restorations in vivo. J Dent Res 62:904-906. https://doi. org/10.1177/00220345830620081101

18. De Munck J, Van Landuyt K, Peumans M et al (2005) A critical review of the durability of adhesion to tooth tissue: methods and results. J Dent Res 84:118-132. https://doi.org/10.1177/ 154405910508400204 
19. Heintze SD (2013) Clinical relevance of tests on bond strength, microleakage and marginal adaptation. Dent Mater Off Publ Acad Dent Mater 29:59-84. https://doi.org/10.1016/j.dental.2012.07.158

20. Gordan VV, Shen C, Riley J, Mjör IA (2006) Two-year clinical evaluation of repair versus replacement of composite restorations. J Esthet Restor Dent Off Publ Am Acad Esthet Dent Al 18:144-153; discussion 154. https://doi.org/10.1111/j.1708-8240.2006.00007.x

21. Ferracane JL, Mitchem JC (2003) Relationship between composite contraction stress and leakage in Class V cavities. Am J Dent 16:239-243

22. Maske TT, Hollanders ACC, Kuper NK, Bronkhorst EM, Cenci MS, Huysmans MCDNJM (2019) A threshold gap size for in situ secondary caries lesion development. J Dent 80:36-40. https://doi. org/10.1016/j.jdent.2018.10.014

23. Naumann M, Blankenstein F, Kiessling S, Dietrich T (2005) Risk factors for failure of glass fiber-reinforced composite post restorations: a prospective observational clinical study. Eur J Oral Sci 113: 519-524. https://doi.org/10.1111/j.1600-0722.2005.00257.x

24. Naumann M, Reich S, Nothdurft FP et al (2008) Survival of glass fiber post restorations over 5 years. Am J Dent 21:267-272

25. Muliyar S, Shameem KA, Thankachan RP, Francis PG, Jayapalan CS, Hafiz KA (2014) Microleakage in endodontics. J Int Oral Health JIOH 6:99-104

26. Başaran EG, Ayna E, Halifeoğlu M (2012) Microleakage of endodontically treated teeth restored with 3 different adhesive systems and 4 different fiber-reinforced posts. J Prosthet Dent 107:239-251. https://doi.org/10.1016/S0022-3913(12)60069-9

27. Zeiger DN, Sun J, Schumacher GE, Lin-Gibson S (2009) Evaluation of dental composite shrinkage and leakage in extracted teeth using X-ray microcomputed tomography. Dent Mater Off Publ Acad Dent Mater 25:1213-1220. https://doi.org/10.1016/j. dental.2009.04.007

28. Kakaboura A, Rahiotis C, Watts D, Silikas N, Eliades G (2007) 3Dmarginal adaptation versus setting shrinkage in light-cured microhybrid resin composites. Dent Mater Off Publ Acad Dent Mater 23:272-278. https://doi.org/10.1016/j.dental.2006.01.020

29. Sun J, Eidelman N, Lin-Gibson S (2009) 3D mapping of polymerization shrinkage using X-ray micro-computed tomography to predict microleakage. Dent Mater Off Publ Acad Dent Mater 25:314 320. https://doi.org/10.1016/j.dental.2008.07.010

30. Hirata R, Clozza E, Giannini M, Farrokhmanesh E, Janal M, Tovar N, Bonfante EA, Coelho PG (2015) Shrinkage assessment of low shrinkage composites using micro-computed tomography. J Biomed Mater Res B Appl Biomater 103:798-806. https://doi. org $/ 10.1002 / \mathrm{jbm}$. b.33258

31. Scotti N, Michelotto Tempesta R, Pasqualini D et al (2020) 3D interfacial gap and fracture resistance of endodontically treated premolars restored with fiber-reinforced composites. J Adhes Dent 22: 215-224. https://doi.org/10.3290/j.jad.a44286

32. Scotti N, Baldi A, Vergano EA, Tempesta RM, Alovisi M, Pasqualini D, Carpegna GC, Comba A (2020) Tridimensional evaluation of the interfacial gap in deep cervical margin restorations: a micro-CT study. Oper Dent 45:E227-E236. https://doi.org/10.2341/19-161-L

33. Reeh ES, Messer HH, Douglas WH (1989) Reduction in tooth stiffness as a result of endodontic and restorative procedures. J Endod 15:512 516. https://doi.org/10.1016/S0099-2399(89)80191-8

34. Lassila LVJ, Tanner J, Le Bell A-M et al (2004) Flexural properties of fiber reinforced root canal posts. Dent Mater Off Publ Acad Dent Mater 20:29-36. https://doi.org/10.1016/s0109-5641(03)00065-4

35. Novais VR, Versluis A, Correr-Sobrinho L, Soares CJ (2011) Three-point bending testing of fibre posts: critical analysis by finite element analysis. Int Endod J 44:519-524. https://doi.org/10.1111/ j.1365-2591.2011.01856.x

36. Hattori M, Takemoto S, Yoshinari M et al (2010) Durability of fiber-post and resin core build-up systems. Dent Mater J 29:224 228. https://doi.org/10.4012/dmj.2009-113
37. Seefeld F, Wenz H-J, Ludwig K, Kern M (2007) Resistance to fracture and structural characteristics of different fiber reinforced post systems. Dent Mater Off Publ Acad Dent Mater 23:265-271. https://doi.org/10.1016/j.dental.2006.01.018

38. Mannocci F, Bertelli E, Sherriff M, Watson TF, Pitt Ford TR (2009) Three-year clinical comparison of survival of endodontically treated teeth restored with either full cast coverage or with direct composite restoration. 2002. Int Endod J 42:401-405. https://doi.org/ 10.1111/j.1365-2591.2009.01559.x

39. Sorensen JA, Martinoff JT (1984) Intracoronal reinforcement and coronal coverage: a study of endodontically treated teeth. J Prosthet Dent 51:780-784

40. Ng CCH, Dumbrigue HB, Al-Bayat MI et al (2006) Influence of remaining coronal tooth structure location on the fracture resistance of restored endodontically treated anterior teeth. J Prosthet Dent 95: 290-296. https://doi.org/10.1016/j.prosdent.2006.02.026

41. Signore A, Benedicenti S, Kaitsas V, Barone M, Angiero F, Ravera G (2009) Long-term survival of endodontically treated, maxillary anterior teeth restored with either tapered or parallel-sided glassfiber posts and full-ceramic crown coverage. J Dent 37:115-121. https://doi.org/10.1016/j.jdent.2008.10.007

42. Tjan AH, Grant BE, Dunn JR (1991) Microleakage of composite resin cores treated with various dentin bonding systems. J Prosthet Dent 66:24-29. https://doi.org/10.1016/0022-3913(91)90346-x

43. Yang HS, Lang LA, Molina A, Felton DA (2001) The effects of dowel design and load direction on dowel-and-core restorations. J Prosthet Dent 85:558-567. https://doi.org/10.1067/mpr.2001.115504

44. Bolay Ș, Öztürk E, Tuncel B, Ertan A (2012) Fracture resistance of endodontically treated teeth restored with or without post systems. J Dent Sci 7:148-153. https://doi.org/10.1016/j.jds.2012.03.011

45. Vadini M, De Angelis F, D'Amario M et al (2012) Conservative restorations of endodontically compromised anterior teeth in paediatric patients: physical and mechanical considerations. Eur J Paediatr Dent Off J Eur Acad Paediatr Dent 13:263-267

46. von Stein-Lausnitz M, Bruhnke M, Rosentritt M, Sterzenbach G, Bitter K, Frankenberger R, Naumann M (2019) Direct restoration of endodontically treated maxillary central incisors: post or no post at all? Clin Oral Investig 23:381-389. https://doi.org/10.1007/ s00784-018-2446-6

47. Newman MP, Yaman P, Dennison J, Rafter M, Billy E (2003) Fracture resistance of endodontically treated teeth restored with composite posts. J Prosthet Dent 89:360-367. https://doi.org/10. 1067/mpr.2003.75

48. Strassler HE, Cloutier PC (2003) A new fiber post for esthetic dentistry. Compend Contin Educ Dent Jamesburg NJ 1995 24: 742-744, 746, 748 passim

49. Abduljawad M, Samran A, Kadour J, Karzoun W, Kern M (2017) Effect of fiber posts on the fracture resistance of maxillary central incisors with class III restorations: an in vitro study. J Prosthet Dent 118:55-60. https://doi.org/10.1016/j.prosdent.2016.09.013

50. Fadag A, Negm M, Samran A, et al (2018) Fracture resistance of endodontically treated anterior teeth restored with different post systems an in vitro study. 10.14744/eej.2018.0003

51. Hayashi M, Takahashi Y, Imazato S, Ebisu S (2006) Fracture resistance of pulpless teeth restored with post-cores and crowns. Dent Mater Off Publ Acad Dent Mater 22:477-485. https://doi.org/10. 1016/j.dental.2005.03.017

52. Chieruzzi M, Pagano S, Cianetti S, Lombardo G, Kenny JM, Torre L (2017) Effect of fibre posts, bone losses and fibre content on the biomechanical behaviour of endodontically treated teeth: 3D-finite element analysis. Mater Sci Eng C Mater Biol Appl 74:334-346. https://doi.org/10.1016/j.msec.2016.12.022

Publisher's note Springer Nature remains neutral with regard to jurisdictional claims in published maps and institutional affiliations. 